REVIEW ARTICLE

\title{
Brazilian Jiu-Jitsu Needs Analysis
}

\section{Trevor Shaw*}

Palmer College of Chiropractic, USA

*Corresponding author: Trevor Shaw, Palmer College of Chiropractic, Florida Campus, USA

\section{Introduction}

The physical nature and needs of the athletes in the sport of Brazilian jiu-jitsu are unique. Depending on the style and competition selection, athletes are exposed to a wide variety of match times, making the endurance, strength, and even flexibility demands variable. Beginner matches start at a length of $5 \mathrm{~min}$ utes, where high-level competition can go up to 20 minutes in a single round. Each of these requires very different physical attributes depending on the style of the bout. For the sake of this article, we will discuss the needs of the beginner competing in a 5-minute match, as that is the most common division.

The sport of Brazilian Jiu-Jitsu requires high levels of aerobic conditioning, anaerobic power, strength, flexibility. The athlete must be able to explode with strength and speed but also demonstrate a solid foundation of endurance to continue for five straight minutes of grappling. It is, therefore, the job of the exercise scientists to perform the needs analysis of each competitor to make sure any attribute is not lacking.

Aerobic power can be considered the foundation of a competitive Brazilian Jiu-Jitsu athlete. Five-minute matches have the potential to be slow and methodical similar to human chess or non-stop high-speed grappling. The athlete's ability to demonstrate aerobic power is essential for both circumstances, particularly the latter. [1] showed that due to the high effort to pause ratio, Brazilian Jiu-Jitsu is mostly an aerobic sport with moderate contributions from the glycolytic system. Physiologically this means our athletes need to demonstrate more prolonged bouts of energy more with more aerobic efficiency [2] to prevent early fatigue. To test aerobic power, the exercise specialist would use the Bruce treadmill test to analyze the $\mathrm{VO}_{2}$ max. [1] note that the average $\mathrm{VO}_{2}$ max in their competitive Brazilian Jiu-Jitsu cohort was $49.4 \mathrm{ml} / \mathrm{kg}$ per minute. Andreato, Lara, [3] also stated the numbers were between 42 and $52 \mathrm{ml} / \mathrm{kg}$ in their secondary study. According to [4], this would be considered a high $\mathrm{VO}_{2}$ max in the $99^{\text {th }}$ percentile. Athletes who fall short of these recommendations will benefit from increasing aerobic power training.

The anaerobic needs of the Brazilian Jiu-Jitsu athlete are essential as well. With numerous bouts of explosive energy demonstrated in each match, the athlete must have a foundation of anaerobic power. These athletes must have a solid base, so early fatigue in strenuous bouts doesn't set in prematurely. To test this anaerobic capacity, the 40-yard dash can be used with minimal space and cost [2]. The unpublished work by Stuart, Powers, and Nelson [3], cited in [2], discusses the multiple 40-yard dashes with 25 second timed breaks as an applicable test for American football players. Due to similar demands and bouts of aerobic vs. anaerobic output, the exercise specialist can safely use this standard when testing their competitive Brazilian Jiu-Jitsu athletes. In their observational work, "Development of an anaerobic fitness test for football players," Stuart, Powers, and Nelson state that their protocol mimics the style of competition output more closely than other forms of anaerobic testing such as the single 40 or 100-meter dash. Such a test may be more beneficial than the standard 40-yard dash for Brazilian Jiu-Jitsu athletes as the sport requires multiple bursts of energy with minimal recovery. [5] state that a recreational collegiate aged athlete should run a 5.0-second 40-yard dash. Depending on the level of competitiveness of the athlete, this may be a good standard of comparison.

Strength is also a crucial part of any combat sport not only because of the physical implications but for in-

Citation: Shaw T (2020) Brazilian Jiu-Jitsu Needs Analysis. Int J Sports Exerc Med 6:162. doi. org/10.23937/2469-5718/1510162

Accepted: April 21, 2020; Published: April 23, 2020

Copyright: (c) 2020 Shaw T. This is an open-access article distributed under the terms of the Creative Commons Attribution License, which permits unrestricted use, distribution, and reproduction in any medium, provided the original author and source are credited. 
jury prevention purposes as well. [4] demonstrated how maximal dynamic, isometric, and endurance strength were valuable components of the competitive Brazilian Jiu-Jitsu athlete and could be associated with positive competitive outcomes. Neurologically there are two ways we get stronger. First, there is a firing of motor units at a faster rate until $10 \mathrm{~Hz}$ is reached, once this threshold is reached more motor units begin to get recruited to keep up with the growing demand [6]. Developing both aspects of motor unit expression is essential for performance.

The one reps max test can test the athlete's overall strength capability. Dictated by the ratio of fast to slowtwitch fibers, the ability to execute a single repetition max effort on the bench press and squat is essential to performance in Brazilian Jiu-Jitsu. According to [7], a 20-29-year-old male should be able to bench press 1.63 times their body weight and women 1.01 times body weight to be considered superior. As for the lower body, and above-average males in their 20 's should be able to leg press 2.27 times bodyweight, 1.82 percent for females [7]. [8] noted the importance of core strength in Brazilian Jiu-Jitsu fighters whose game was geared more towards guard passing than guard fighting leading us to evaluated and program accordingly based on style.

Flexibility is also a significant factor in the development of a competitive Brazilian Jiu-Jitsu athlete. Often, people mistake a joints range of motion for flexibility. These are two very different things. Flexibility is the extensibility of the soft tissue around the joint, whereas the range of motion pertains to the joint structure itself. Flexibility in Brazilian Jiu-Jitsu is critical so that athletes can navigate any of the numerous awkward positions martial artists can find themselves in [9] discovered poor flexibility in their evaluative cohort, indicating an ahead of the need for the competitive athlete. To assess this flexibility, the NSCA recommends the sit and reach test. This test aids in the evaluation of posterior chain extensibility and can clue the coaches to the need for further as- sessment or management in the area of flexibility. An athlete must reach over 24.0 inches to be considered in the $99^{\text {th }}$ percentile and 20 inches to be in the $50^{\text {th }}$ percentile.

Brazilian Jiu-Jitsu is a complex sport requiring many different attributes, from aerobic and anaerobic power to strength and flexibility. Athletes who don't meet the minimum standards may benefit from programs built to maximize their qualities while bringing their weaknesses up to par.

\section{References}

1. Andreato LV, Moraes SFD, Gomes TLDM, Esteves JDC, AndreatoTV, et al. (2011) Estimated aerobic power, muscular strength and flexibility in elite Brazilian Jiu-Jitsu athletes. Science \& Sports 26: 329-337.

2. Powers SK, Howley ET (2018) Exercise physiology: Theory and application to fitness and performance. New York, NY: McGraw-Hill Education.

3. Stuart M, Powers S, Nelson J (2018) Development of an anaerobic fitness test for football players. (Unpublished observations). Retrieved from: Powers \& Howley.

4. Andreato LV, Lara FJD, Andrade A, Branco BHM (2017) Physical and Physiological Profiles of Brazilian Jiu-Jitsu Athletes: a Systematic Review. Sports Med Open 3: 9.

5. Baechle TR, Earle RW (2008) NSCAs Essentials of Strength and Conditioning. ( $3^{\text {rd }}$ edn), Champaign, IL: Human Kinetics.

6. Weiss J, Weiss LD, Silver JK, Dowling DJ (2016) Easy EMG: a guide to performing nerve conduction studies and electromyography. Edinburgh: Butterworth-Heinemann.

7. Riebe D, Ehrman JK, Liguori G, Magal M (2018) ACSMs guidelines for exercise testing and prescription. Philadelphia: Wolters Kluwer.

8. Lima PO, Lima AA, Coelho AC, Lima YL, Almeida GP, et al. (2017) Biomechanical differences in brazilian jiu-jitsu athletes: the role of combat style. Int J Sports Phys Ther 12: $67-74$.

9. Andreato LV, Santos JF, Esteves JV, Panissa VL, Julio UF, et al. (2016) Physiological, Nutritional and Performance Profiles of Brazilian Jiu-Jitsu Athletes. J Hum Kinet 53: 261 271. 